\title{
Interactive comment on "Plant trait response of tundra shrubs to permafrost thaw and nutrient addition" by Maitane Iturrate-Garcia et al.
}

\section{Michael O’Brien}

mikey.j.obrien@gmail.com

Received and published: 19 April 2020

I found the manuscript clear and well written. I think it provides a nice contribution to climate change impacts in the arctic system. Here are a few line-by-line comments.

L12: I would not use the word adapt as that implies a genetic response, which is not tested here. L62: I find this reference to Voille odd. I would say performance traits (detailed in Voille et al. 2007). L66: Remove 'however' L120: When were these sampled? At the beginning and end of the experiment? Only after the 4 years? L168 \& L174: The model is actually block, heat treatment, fert treatment and treatment interaction. Not solely the interaction. I think the description of the analysis could use a bit of revision for clarity. It is often written in a condensed way that makes it tough to 
follow. I would add a bit of text to improve clarity of the model descriptions, especially for the contrasts. L203: I am not sure 'no-growing' is correct, maybe 'dormant' L266-267: Shrubs are plants, so this is redundant. L269: Confusing. Try: "Shrubs were released from growth limitation via nutrient addition, which was evidenced by..." or "Nutrient addition released shrubs from growth limitation as evidenced by. .." L289-291: Which species would outcompete shrubs in this system? Which species will shade them out? L301: evergreen and deciduous are not species but PFT and if you mean species then use among not between. L310: Did you test wood density in tissues grown before and after treatment? It seems like the sampling strategy would allow partitioning the inner and outer stem to see differences. L320: It is not clear regarding the point that stem and leaf trade-offs operate independently. Please revise for clarity. L349: Remove 'also' L357: Confusing sentence. L322-370: I found the discussion overly speculative in an effort to relate the trait responses into a climate-vegetation feedback. I would encourage the authors reduce the speculation or possibly present the information as potential scenarios of climate and vegetation responses. Fig 5: Could you inverse two of the PC1 values so that the $\mathrm{x}$-axis is always conservative on the left side and acquisitive on the right? It would make it easier to read.

Interactive comment on Biogeosciences Discuss., https://doi.org/10.5194/bg-2019-498, 2020. 